Research article

\title{
Assessing the knowledge of bronchial asthma among primary health care physicians in Crete: A pre- and post-test following an educational course

\author{
Emmanouil Rovithis $^{* 1}$, Christos Lionis ${ }^{1,2}$, Sofia E Schiza ${ }^{3}$, \\ Dimosthenis Bouros ${ }^{3}$, Antonis Karokis ${ }^{1}$, loannis Vlachonikolis ${ }^{4}$ and \\ Nikolaos M Siafakas ${ }^{3}$
}

\begin{abstract}
Address: ${ }^{1}$ Clinic of Social and Family Medicine, Department of Social Medicine, School of Medicine, University of Crete, 71409 Heraklion, Crete, Greece, , ${ }^{2}$ Department of Medicine and Care, Faculty of Health Sciences, University of Linkoping, Sweden,, ${ }^{3}$ Department of Thoracic Medicine, University Hospital of Heraklion, Crete, Greece and ${ }^{4}$ Biostatistics Laboratory, Department of Social Medicine, University of Crete, Greece

E-mail: Emmanouil Rovithis* - manrovit@med.uoc.gr; Christos Lionis - lionis@med.uoc.gr; Sofia E Schiza - sschiza@dep.forthnet.gr; Dimosthenis Bouros - bouros@med.uoc.gr; Antonis Karokis - lionis@med.uoc.gr; loannis Vlachonikolis - I.Vlachonikolis@surrey.ac.uk; Nikolaos M Siafakas - siafakas@med.uoc.gr

${ }^{*}$ Corresponding author
\end{abstract}

\begin{abstract}
Aim: To assess the level of knowledge for bronchial asthma of the primary healthcare physicians serving a rural population on the island of Crete, both before and immediately after a one-day educational course.

Methods: Twenty-one primary health care physicians, randomly selected from a list of 14 Health Care Centres on the island of Crete were invited to participate in the study and attended an educational course. Nine of the $2 \mathrm{I}$ physicians were fully qualified general practitioners, while the remainder were non-specialized (NSs) physicians who had recently graduated from the University of Crete, Medical School. A questionnaire of 20 items based on current bronchial asthma clinical guidelines was used. Three scores, the mean total, knowledge subscore and attitudes subscore, were calculated for each group of physicians, both before and after the course.

Results: At baseline mean total score and knowledge and attitudes subscores were higher for non-specialized physicians than for the general practitioners, but the differences were not statistically significant $(p>0.05)$. The knowledge subscore was improved in both groups, however the difference was statistically significant only for the non-specialized physicians $(t=2.628$, d.f. $=$ $\mathrm{II}, \mathrm{p}<0.05$ ). The mean total score after the course was significantly higher for the non-specialized physicians in comparison to that of the general practitioners $(t=-2.688$, d.f. $=19, p<0.05)$.

Conclusions: This study adds to the information about the success of continuing medical education, and also demonstrates that the recent graduates in the studied population, could be educated with more positive results than the fully qualified practitioners
\end{abstract}

\section{Background}

Bronchial asthma appears to be a major public health problem in Greece [1,2]. Although exact epidemiological data is lacking, its prevalence is estimated to be approximately $5.5 \%$ of the general population [1]. The majority of asthma patients living in rural areas are managed by 
general practitioners and non-specialized primary health care physicians.

Previous studies from other countries that have investigated the level of knowledge of bronchial asthma and the competence of primary care physicians in management issues, concluded that there is a substantial variation among General Practitioners [3-8] in both their knowledge and management practices, including the assessment of the severity of asthma, the monitoring of the asthmatic patient and the use of proper medications.

Educational programmes based on self - learning in small peer groups, seem to be effective in improving asthma management [9]. Similar programmes have not yet been implemented in Greece, a country in which general practice has only recently been recognised as an independent medical specialty and academic discipline.

It was therefore interesting to implement an educational intervention with the main objectives being: a) to explore its effect on primary health care physicians in rural Crete, (b) to improve the treatment of asthma patients in this setting.

This study reports the pre- and post-test results for the assessment of knowledge of the current asthma guidelines for two groups of primary care physicians, who attended a one-day educational course on the asthma practice guidelines.

\section{Methods}

\section{Study participants}

Twenty-one primary health care physicians (PHC) were randomly selected from all 14 Health Centres serving rural Crete and were invited to participate in the study. Nine of them were fully qualified General Practitioners (GPs) while the remainder were young physicians without a medical specialty (NSs), who had recently graduated from the Medical School of the University of Crete and were serving an annual elective term at the primary health care setting. The participating GPs represented approximately $25 \%$ of the total number of the GPs working on Crete.

\section{The educational course}

The participating physicians attended an intensive educational course on bronchial asthma, focusing on diagnostic and management issues in the light of asthma guidelines set forth by the National Heart, Lung, and Blood Institute (NHLBI) Expert Panel Report - 2 (EPR2) [10]. These guidelines have been translated and distributed throughout Greece. The aim of the educational course was the presentation of the NHLBI - EPR-2 asthma guidelines. Lectures given by respiratory medicine specialists, from the Department of Thoracic Medicine University Hospital, Crete, focused on the following topics: a) Definition and pathogenesis of bronchial asthma with emphasis on the inflammatory nature of the disease, b) measures of assessment, monitoring of asthmatic patients, and goals of therapy, c) initial assessment, diagnosis, differential diagnosis and periodic follow-up of patients, d) control of factors that trigger an attack or aggravate asthma, e) pharmacological therapy with detailed presentation of anti-asthmatic medications f) classification (staging) of asthma according to severity, g) stepwise approach in asthma management, h) patient education. Finally, there were demonstrations about peak expiratory flow (PEF) measurement and inhalation techniques.

\section{Outcome measurement}

A 20 item questionnaire was administered to the participants and completed anonymously, both before and immediately after the end of the course. (Table 1). The questions, which had been pretested and applied in previous studies, were selected from the following sources: a) Pulmonary Medicine and Critical Care Medical Knowledge Self-Assessment Programme, b) The $11^{\text {th }} \mathrm{Na}$ tional American College of Chest Physicians Pulmonary Board Review Syllabus. The extent to which knowledge and attitudes were in agreement with the NHLBI guidelines was also assessed.

Knowledge about World Health Organization - NHLBI asthma definition, predisposing, risk and trigger factors, diagnosis and differential diagnosis was assessed (11 questions in total). Attitude statements dealt with staging of chronic asthma, maintenance treatment, treatment of asthma exacerbations, PEF measurement and patient self-management (in total 9 questions, including 4 clinical cases).

\section{Statistical analysis}

There was only one correct answer to each of the 20 questions and if correct each answer contributed by one point therefore the maximum possible total was 20 points. The total score and two subscores, the knowledge subscore (KSc) and attitudes subscore (ASc), were calculated twice, before (baseline) and also after the course. For each group, differences in these three scores between the two occasions (pre- and post-course) were assessed by the t-test for paired comparisons or the Wilcoxon test (non-parametric test for matched pairs) [11]. Similarly, for each occasion, the differences between groups were assessed by the t-test for independent samples or the non-parametric test (Mann-Whitney) [11]. As the results were similar between parametric and non-parametric tests, only the parametric ones are shown (Table 2). 
Table I: Descriptive presentation of the questions that formed the questionnaire used in the study.

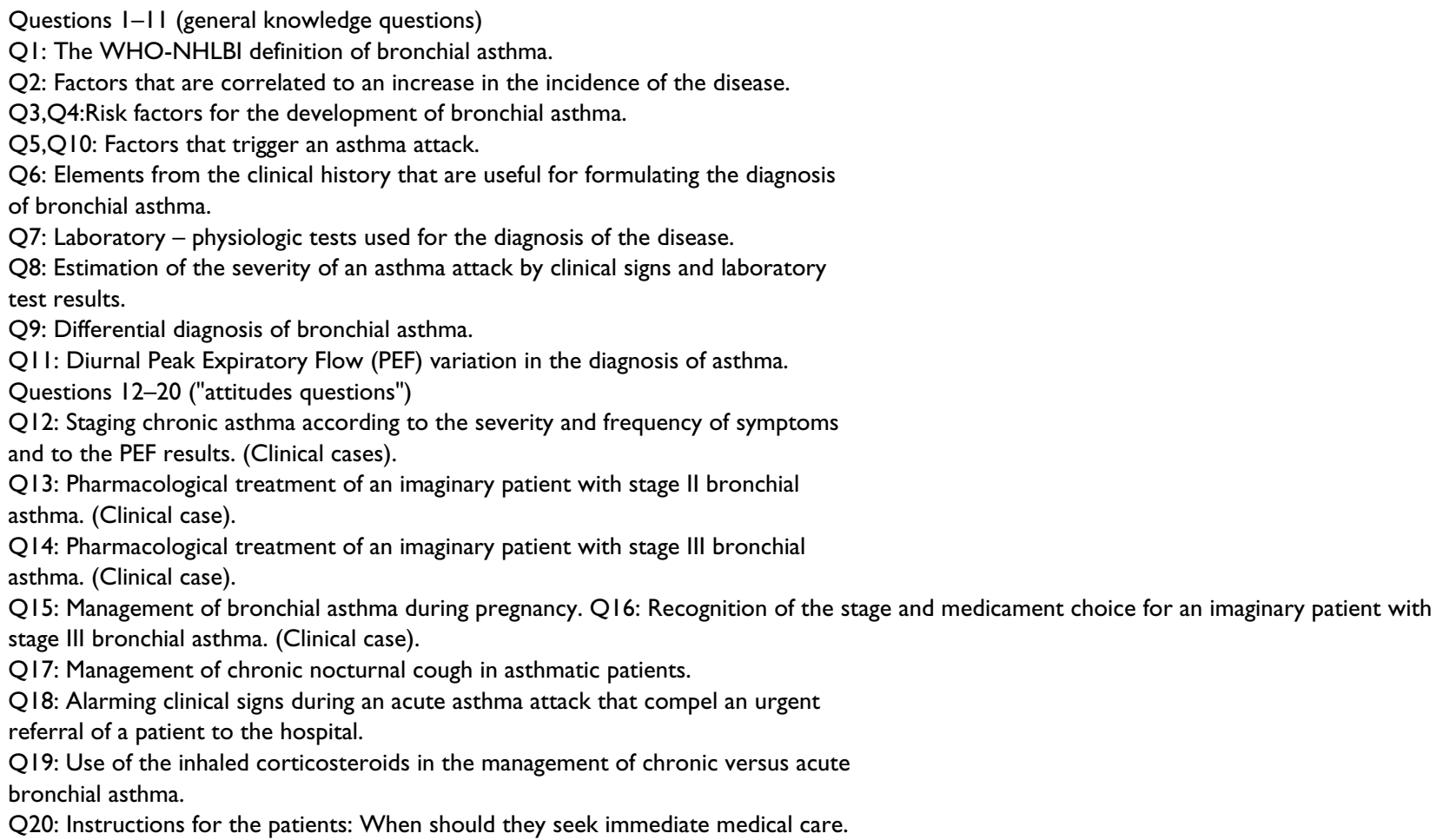

\section{Results}

The mean scores for the two groups of physicians, before and after the course (total, KSc, ASc) are shown on Table 2. The NSs scored higher at the baseline than the GPs in the mean total, KSc and ASc but the differences between the two groups of physicians were not statistically significant $(p>0.05)$.

Both groups increased their level of knowledge (mean total score) between the two occasions (before and after the course) but only for the NSs was the difference found to be statistically significant $(\mathrm{t}=3.326$, d.f. $=11, \mathrm{p}<0.01)$. The KSc improved after the course for both groups, but the difference was again, only statistically significant for the NSc $(t=2.628$, d.f. $=11, p<0.05)$. The mean ASc score of the two groups also improved after the course, the difference between the two occasions was found to be significant for both the GPs $(\mathrm{t}=3.024$, d.f. $=8, \mathrm{p}<0.05)$, and the NSs $(\mathrm{t}=3.362$, d.f. $=11, \mathrm{p}<0.01)$.

The mean total score for the NSs, after the course, was significantly higher, in comparison with that of the GPs $(t=-2.688$, d.f. $=19, p<0.05)$. The differences between the two groups were also significant in favour of the NSs in both KSc, $(\mathrm{t}=-2.122$, d.f. $=19, \mathrm{p}<0.05)$, and ASc scores $(t=-2.294$, d.f. $=19, p<0.05)$.

\section{Discussion}

Some methodological limitations should be discussed before attempting any interpretation of the findings of this study. The number of participating physicians was small, however it could be considered as representative of those GPs serving in rural areas of Crete. Questions could also be raised about the validity and reliability of the questionnaire used to assess the level of knowledge of the physicians on bronchial asthma. Content validity had been previously tested by the Clinic of Respiratory Medicine, University Hospital of Heraklion. Moreover the questionnaire had been pretested with any confounding questions being either clarified or eliminated.

Apart from these important methodological considerations the main finding of this study is that both groups of physicians did poorly in their knowledge assessment as reflected by their low scores at the baseline. It is difficult to assess whether this finding arises from a difficult examination, or a lack of knowledge on the part of those taking part in the pre-test.

Especially worrisome is the fact that GPs presented an overall lower score in comparison to this of the NSs. This puzzling finding possibly arises from the recent experiences of the NSs who were used to being educated by 
Table 2: Mean total, knowledge and attitude scores of the two groups and comparison between groups before and after the course.

\begin{tabular}{llll}
\hline Mean Score & GPs & NSs & Level of sig. \\
\hline $\begin{array}{l}\text { Total score } \\
\text { Before (baseline) }\end{array}$ & 11.33 & $12.83^{+}$ & n.s \\
After & 12.77 & $15.58^{+}$ & $\mathrm{P}<0.05$ \\
Knowledge score & & $7.25^{*}$ & $\mathrm{n} . \mathrm{s}$ \\
Before (baseline) & 6.77 & $8.75^{*}$ & $\mathrm{P}<0.05$ \\
After & 6.88 & $5.58^{+}$ & $\mathrm{n} . \mathrm{s}$ \\
Attitude score & & $6.83^{+}$ & $\mathrm{P}<0.05$ \\
Before (baseline) & $4.55^{*}$ & & \\
After & $5.88^{*}$ & & \\
\hline
\end{tabular}

n.s: not significant, $+: \mathrm{p}<0.01,{ }^{*}: \mathrm{p}=0.05$.

courses of this type at the Medical School of the University of Crete, whereas for the GP's who have either not attended educational courses for many years or have become used to other methods of learning, this approach seems ineffective. Other factors that could explain this finding are: a) the lack of training of the GPs in respiratory medicine during their vocational training, b) the lack of dissemination of the current EPR-2 guidelines on bronchial asthma among the GPs in Greece, c) the fact that all of the NS's were newly graduated and had only recently been exposed to the EPR-2 guidelines.

In the KSc a disappointing finding was the very small percentage of correct answers in the question that referred to the definition of bronchial asthma. The majority of the physicians in both groups appeared to be unaware of the current definition which stressed the inflammatory nature of the disease.

The low scores for both groups to the "attitudes questions" which assessed the staging of chronic bronchial asthma and the indicated drug therapy, was especially disturbing Further emphasis should be given to this finding, when implementing future educational programmes.

An important question is whether the observed deficiencies in knowledge, of both the GP's and NS's are reflected in their actual clinical practice. A similar study recently carried out in Greece, revealed that PHCPs were prescribing for asthmatic patients in an obsolete manner, mainly because the extent of their knowledge of the current asthma guidelines was scant [12]. Although our questionnaire was designed to assess the knowledge of the physicians of the EPR-2 guidelines and not their actual management practices, the combination of our find- ings with those of the aforementioned study does not leave much room for optimism.

On the basis of the results of this study it is still unknown if our educational course was effective or not. We are uncertain as to whether the success of the newly graduated NSs can be attributed to the lecture-based intensive course or related more to their recent educational experiences. Our test was not repeated, therefore no data about its later effectiveness is available.

The findings of our study seem to have serious implications on both, asthma management and educational programmes for primary care physicians. First, they stress the compelling need for the development of continued medical education (CME) programmes for the GPs and PHC physicians focusing on asthma guidelines. Previous studies of CME effectiveness have shown that these programmes should include "enabling" (facilitating practical application of new knowledge into every day clinical practice) and reinforcing components [13,14]. Secondly, they may have an impact on the existing vocational training programme in General Practice in Greece, with a strong recommendation for a period of training in respiratory medicine being incorporated in the educational scheme. Finally, the clear messages of this study should be taken into account by health planners, hospital physicians and primary care groups in Greece, when a national educational strategy will be implemented.

In conclusion, although this study may over-estimate the effect of the educational course, it adds to the information about the success of continuing medical education endeavours, and demonstrates that newly graduated NS physicians are more receptive to educational pro- 
grammes and have more positive results than fully qualified physicians.

\section{Competing interests}

None declared

\section{Acknowledgements}

I. This study was supported by a grant received by the ASTRAZENECA HELLAS.

2. We are grateful to Dr. David Cook for his valuable and very cohesive comments and remarks on the result's interpretation.

\section{References}

I. Siafakas NM, Vlasserou FN: Epidemiology of Bronchial Asthma. In Bronchial Asthma, Simposion in the context of the 19th Annual Panhellenic Medical Conference, Medical Association of Athens, Athens 1993

2. Charokopos S, Priftis K, Orfanou E, Saxoni-Papageorgiou F, Chaidas A: Afksisi ton Isagogon asthmatikon pedion sta nosokomeia tis Athinas (Increase in admission rates for asthmatic children in hospitals of Athens). Pediatriki 1992, 55:17

3. Fardy HJ, Jeffs D: Assessment of general practitioners' asthma knowledge. Aust Fam Physician 1991, 20: I|43-I|44

4. Lagerlov $\mathrm{P}$, Veninga CC, Muskova M, Hummers-Pradier E, Stalsby Lundborg C, Andrew M, Haaijer-Ruskamp FM: Asthma management in five European countries: doctors' knowledge, attitudes and prescribing behaviour. Drug Education Project (DEP) group. Eur Respir J 2000, I 5:25-29

5. Collins S, Beilby J, Fardy J, Burgess T, Johns R, Booth B: The national asthma audit. Bridging the gap between guidelines and practice. Aust Fam Physician 1998, 27:907-913

6. Coates JR, Steven IUD, Beilby J, Coffey G, Litt JC, Wagner C: Knowledge of and reported asthma management among South Australian general practitioners. Br J Gen Pract 1994, 44: I 23-I 26

7. Tomson Y, Hasselstrom J, Tomson G, Aberg H: Asthma education for Swedish primary care physicians - a study on the effects of "academic detailing" on practice and patient knowledge. Eur J Clin Pharmacol 1997, 53:19|-196

8. Barker $\mathrm{BH}$ : Last breath. A general practice study of asthma knowledge. Aust Fam Physician 1987, 6:548-558

9. Veninga CC, Lagerlov P, Wahlstrom R, Muskova M, Denig P, Berkhof J, Kochen MM, Haaijer-Ruskamp FM: Evaluating an Educational Intervention to improve the treatment of Asthma in four European Countries. Au. J Respir Crit. Care Med. 1999, I 60:I2541262

10. National Institutes of Health, National Heart, Lung, and Blood Institute: Guidelines for the Diagnosis and Management of Asthma - Expert Panel Report 2. USA 1997

I I. Campbell MJ, Machin D: Medical Statistics: a commonsense approach. (3rd Ed.), Chichester, UK, John Wiley \& Sons 1999

12. Gourgoulianis KI, Ramos B, Christou K, Rizopoulou D, Efthimiou A: Prescription of medications by primary care physicians in the light of asthma guidelines. Respiration 1998, 65 (I): 18-20

13. Davis DA, Thomson MA, Oxman AD, Haynes RD: Evidence for the effectiveness of CME: a review of $\mathbf{5 0}$ randomized controlled trials. JAMA. 1992, 268: I | II-II|7

14. Manning PR, DeBakey L: Lifelong learning tailored to individual clinical practice. JAMA. 1992, 268: I I35-I I 36

\section{Pre-publication history}

The pre-publication history for this paper can be accessed here:

http://www.biomedcentral.com/content/backmatter/ 1472-6920-1-2-b1.pdf
Publish with BioMed Central and every scientist can read your work free of charge

"BioMedcentral will be the most significant development for disseminating the results of biomedical research in our lifetime." Paul Nurse, Director-General, Imperial Cancer Research Fund

Publish with BMC and your research papers will be:

- available free of charge to the entire biomedical community

- peer reviewed and published immediately upon acceptance

- cited in PubMed and archived on PubMed Central

- yours - you keep the copyright

Submit your manuscript here:

http://www.biomedcentral.com/manuscript/
BioMedcentral.com editorial@biomedcentralcom 